\title{
The influence of relative frequencies of pure and mixed stimuli on mixture suppression in taste
}

\author{
JAN H. A. KROEZE \\ Utrecht University, 3511 BZ Utrecht, The Netherlands
}

\begin{abstract}
In experiments on saltiness suppression in $\mathrm{NaCl}$-sucrose mixtures, the amount of suppression depends not only on the suppressing sucrose component in the mixture, but also on the relative frequencies of pure $\mathrm{NaCl}$ stimuli and mixed stimuli in the series. The observed variation of mixture suppression as a function of these frequencies can be explained by Helson's adaptation level theory.
\end{abstract}

When sucrose and $\mathrm{NaCl}$ are mixed, mutual masking of sweetness and saltiness is observed (Bartoshuk, 1975; Beebe-Center, Rogers, Atkinson, \& O'Connell, 1959; Kroeze, 1978, 1979; Pangborn, 1962; Sjöstrom \& Cairncross, 1953). There are several variables that control the amount of masking in mixture experiments. First and foremost, masking depends upon the type of masking component in the mixture. One component of a certain subjective intensity masks the second component in a binary mixture more than does another compound of identical subjective intensity. For instance, we found that sweetness is masked significantly more in a sucrose/quinine sulfate mixture than in a sucrose $/ \mathrm{NaCl}$ mixture, even when the subjective intensities of all compounds in an unmixed state are identical (Kroeze, 1980).

Another important variable affecting the amount of masking is the physical intensity of the masking component: a weak masking compound suppresses the other compound in the mixture less than does a strong masking compound. Consistent with this rule, $\mathbf{8 7 . 8 \%}$ sweetness suppression was observed in a mixture of .32 M NaCl and .32 M sucrose (Kroeze, 1979) and $42.4 \%$ sweetness suppression in a mixture of $.194 \mathrm{M} \mathrm{NaCl}$ and $.32 \mathrm{M}$ sucrose (Kroeze, in press).

A third variable relevant to the amount of masking is the ratio of the number of unmixed stimuli to the number of mixed stimuli in a specific experiment: thus, if saltiness of an $\mathrm{NaCl}$ /sucrose mixture is estimated, the number of unmixed $\mathrm{NaCl}$ stimuli relative to the number of mixed $(\mathrm{NaCl} /$ sucrose) stimuli in the stimulus series is of importance, which means that a contextual factor plays a role. Four experiments were carried out, each of which had a different $\mathrm{NaCl}$ frequency $/ \mathrm{NaCl}$-frequency $+\mathrm{NaCl}$-sucrose frequency ratio. In the present study, the effect of this contextual

The author's address is: Psychological Laboratory, Utrecht University, Varkenmarkt 2, $3511 \mathrm{BZ}$ Utrecht, The Netherlands. factor (i.e., relative numbers of pure and mixed stimuli) is studied.

\section{METHOD}

Subjects were undergraduate students in the social sciences. They were paid for their participation. The number of subjects in each of the four experiments can be seen in column 2 of Table 1.

In all four experiments, $\mathrm{NaCl}$ and sucrose of reagent grade purity were used as stimuli. The compounds were dissolved in distilled water, and in all experiments both had a concentration of $.32 \mathrm{M} / 1$. The mixture stimuli were equal-volume mixtures of both components. Before mixing the single solutions, their concentrations were doubled in order to obtain the same $(.32 \mathrm{M})$ concentrations of both components in the mixture. All stimuli were delivered by a gravitational flow system consisting of glass containers, silicone flow tubes, and glass-capillary outflow pieces. Capillary outflow rate was $.8 \mathrm{ml} / \mathrm{sec}$. Capillary inner diameter was $.5 \mathrm{~mm}$. Stimulus temperature at the outflow point was $22^{\circ} \mathrm{C}( \pm .5)$. During stimulation, each subject had his tongue in a Perspex tongue box, the size of which was chosen so that it fitted well. The tongue box enabled the experimenter to give a flow stimulus to a fixed 1.3 to $1.5 \mathrm{~cm}^{2}$ area of the left anterior tongue half (exact area depending upon tongue size). The outflow point of the delivery system was about $.75 \mathrm{~cm}$ above the tongue surface. Stimulus duration was $2 \mathrm{sec}$ and the interstimulus interval was $50 \mathrm{sec}$ (Experiments 2, 3, and 4) or $60 \mathrm{sec}$ (Experiment 1). Between stimulus presentations, the tongue was rinsed with distilled water. Dependent upon available time and other aspects not relevant to the present purpose, there were 16,24 , or 48 replications of the mixtures within subjects (column 3, Table 1).

In all four experiments, the subjects responded by positioning a needle along an ungraduated 300 - $\mathrm{mm}$-long linear scale (Kroeze,

Table 1

Overview of the Variables in the Four Taste-Mixture Experiments

\begin{tabular}{cccc}
\hline $\begin{array}{c}\text { Experiment } \\
\text { Number }\end{array}$ & $\begin{array}{c}\text { Number of } \\
\text { Subjects }\end{array}$ & $\begin{array}{c}\text { Number of Mixture } \\
\text { Weplications }\end{array}$ & $\begin{array}{c}\text { N/(N + SN) } \\
\text { Ratio* }\end{array}$ \\
\hline 1 & 6 & 24 & .10 \\
2 & 8 & 16 & .17 \\
3 & 9 & 24 & .50 \\
4 & 12 & 48 & .80 \\
\hline
\end{tabular}

${ }^{*}$ Ratio of number of pure stimuli to the number of mixture and pure stimuli. 
1976). The subjects were instructed to judge the saltiness of the stimuli. Each saltiness judgment was defined as the distance in millimeters from the zero point of the scale, which was the extreme left position of the needle. After each response, the needle was reset to zero by the experimenter.

\section{RESULTS AND DISCUSSION}

The geometric means of the saltiness estimates per subject were used as the dependent variable. The amount of saltiness masking in the mixture was defined as percentage difference between $\mathbf{N}$-saltiness and $\mathrm{SN}$-saltiness, with $\mathrm{N}$-saltiness set at $100 \%$. In Table 2 the geometric means of the individual saltiness judgments of the mixture stimuli are expressed as a percentage of pure $\mathrm{NaCl}$-saltiness. The group means in Table 2 show that masking is dependent upon the relative frequency of the pure $\mathrm{NaCl}$ stimuli to the total number of $\mathrm{N}$ and $\mathrm{SN}$ stimuli: The lower the $\mathrm{N} /(\mathrm{N}+\mathrm{SN})$ ratio, the higher the estimated saltiness of the SN mixture. The differences between the four experiments were tested with a one-way ANOVA for independent groups: $F(3,31)=4.31, p<.02$. It may thus be concluded that the frequency-ratio variable has a significant effect on the subjective saltiness of the SN mixture.

Helson (1964) has proposed a theory that may predict context effects. According to this theory, the adaptation level (AL) is a neutral point on any sort of intensity scale. A stimulus falling on this neutral point is judged as being of intermediate intensity (not weak and not strong). The $\mathrm{AL}$ is quantitatively defined as the geometric mean of the stimuli already presented to a subject. The following discussion is based on this assumption.

The physical intensity (= concentration) of the salty stimuli in the present study is identical for $\mathrm{N}$ and $\mathrm{SN}$

Table 2

Geometric Means of the Individual Saltiness Judgments of the Mixture Stimuli Expressed as a Percentage of Pure-NaCl Saltiness

\begin{tabular}{|c|c|c|c|c|}
\hline & \multicolumn{4}{|c|}{$\mathrm{N} /(\mathrm{N}+\mathrm{SN})$ Frequency Ratio } \\
\hline & .10 & .17 & .50 & .80 \\
\hline & $\begin{array}{r}118.11 \\
73.51 \\
90.33 \\
85.25 \\
88.88 \\
85.82\end{array}$ & $\begin{array}{l}83.67 \\
77.71 \\
67.83 \\
73.68 \\
86.83 \\
93.25 \\
75.22 \\
19.23\end{array}$ & $\begin{array}{r}48.11 \\
67.98 \\
28.42 \\
103.05 \\
13.53 \\
48.64 \\
51.40 \\
59.91 \\
79.13\end{array}$ & $\begin{array}{r}47.54 \\
48.85 \\
39.05 \\
71.66 \\
90.38 \\
17.39 \\
8.82 \\
11.27 \\
103.13 \\
15.78 \\
72.77 \\
24.99\end{array}$ \\
\hline Mean & 90.32 & 72.18 & 55.57 & 45.97 \\
\hline
\end{tabular}

Note-Each column represents a separate and independent experiment with a different context: relative frequency of mixture stimulus (SN) to total stimulus frequency (frequency of $N+S N$ ).

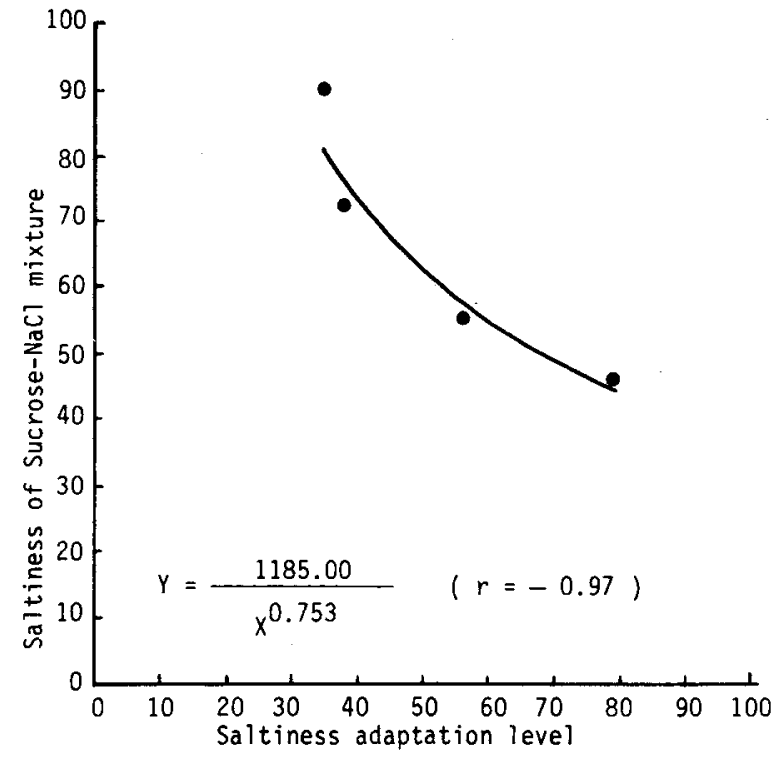

Figure 1. The relationship between adaptation level and mixture saltiness. This function is linear in log-log coordinates and indicates a good fit of the observed results to Helson's adaptation-level concept $(p<.01)$. $X=$ saltiness adaptation level; $Y=$ saltiness of sucrose/ $\mathbf{N a C l ~ m i x t u r e . ~}$

stimuli, both being $.32 \mathrm{M} / 1$. This means that the adaptation level should be constant at $.32 \mathrm{M} / 1$ through the four experiments (insofar as $A L$ is determined by stimulus intensity). In Experiment 3, the number of mixed stimuli is equal to the number of unmixed stimuli and hence the hypothesized $\mathrm{AL}$ cannot depend on differential frequency effects of both types of stimuli. Only intensity must be taken into account here. But the intensity of both types of stimuli is equal. Thus, the AL theory would not predict reduced saltiness in this case. Here, the reduction of saltiness must depend entirely on masking and not on the influence of context. Now it can be asked: What pure $\mathrm{NaCl}$ stimulus must be substituted for the mixture in order to obtain the mean value of $55.57 \%$ saltiness? By applying Helson's general definition of the AL, the following equation must be solved in order to find that value: $\sqrt{100 \times \mathrm{SN}}=55.57$. It then appears that the value to be substituted must have been the stimulus equivalent of a $\mathbf{3 0 . 8 8 \%}$ response value. Starting from the assumption that the exponent of the psychophysical function is 1 , the stimulus equivalent that follows is $30.88 \times .32 \mathrm{M}=.0988 \mathrm{M} / \mathrm{l}$. This stimulus value can now be used to predict the adaptation level in response terms for Experiments 1, 2, and 4, which do not have equal frequencies of $\mathbf{N}$ and $\mathrm{SN}$ :

Experiment 1: $: \sqrt{100 \times 30.88^{9}}=34.73$

Experiment $2: \sqrt[6]{100 \times 30.88^{3}}=37.56$

Experiment $4: \sqrt[3]{100^{4} \times 30.88}=79.06$ 
The resultant $\mathrm{AL}$ values are plotted in Figure 1 along the abscissa. Mixture saltiness is plotted along the ordinate as a function of adaptation level. It can be seen that the AL grows with increasing $N /(N+S N)$ ratio. Now it is clear that the subjective saltiness of SN is inversely related to the adaptation level. The line depicted in Figure 1 is the best-fitting negative power function: $Y=1184.998 / X^{.75286}$, where $Y$ is the saltiness of the mixture and $X$ is the $A L$. This function has a least square fit, after linearization to $\ln \mathrm{Y}=$ $\ln 1184.998-.75286 \ln X$, of $r=-.97$ ( $p<.01)$. It can be concluded that the context effect in our taste experiments is in line with Helson's concept of the adaptation level.

\section{REFERENCES}

BARTOshuK, L. M. Taste mixtures: Is mixture suppression related to compression? Physiology \& Behavior, 1975, 14, 643-649. Befee-Center, J. G., Rogens, M. S., Atkinson, W. H., \& O'ConNell, D. N. Sweetness and saltiness of compound solutions of sucrose and $\mathrm{NaCl}$ as a function of concentration of solutes. Journal of Experimental Psychology, 1959, 57, 231-234. Helson, H. Adaptation-level theory. New York: Harper \& Row, 1964.

Kroeze, J. H. A. Exponential values of the psychophysical power function for sucrose obtained by two different estimations methods. Chemical Senses and Flavor, 1976, 2, 39-43.

Kroeze, J. H. A. The taste of sodium chloride: Masking and adaptation. Chemical Senses and Flavour, 1978, 3, 443-449.

Kroeze, J. H. A. Masking and adaptation of sugar sweetness intensity. Physiology \& Behavior, 1979, 22, 347-351.

Kroeze, J. H. A. Masking in two and three-component taste mixtures. In $\mathrm{H}$. van der Starre (Ed.), Olfaction and taste VII. London: Information Retrieval Ltd., 1980.

Kroeze, J. H. A. A psychophysical study of habituation to $\mathrm{NaCl}$ and sweetness suppression in the $\mathrm{NaCl}$-sucrose mixtures. Chemical Senses, 1982, in press.

Pangborn, R. M. Taste interrelationships 1II: Supra-threshold solutions of sucrose and sodium chloride. Journal of Food Science, 1962, 27, 495-500.

Sjöström, L. B., \& Cairncross, S. E. Role of sweeteners in food flavor. In Advances in chemistry series. Washington, D.C: American Chemical Society, 1953.

(Manuscript received February 20, 1981; revision accepted for publication October 9,1981 .) 